ASLI QoL 2017
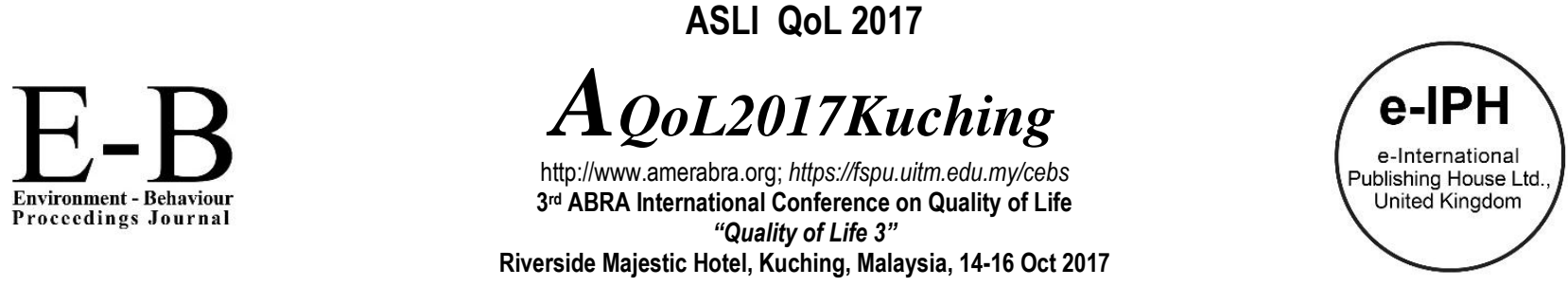

\title{
Perceived Depression, Anxiety and Stress Among UiTM Dental Undergraduates in Clinical Years
}

\author{
1 Centre of Occupational Therapy Studies, Faculty of Health Sciences \\ 2 Centre of Oral \& Maxillofacial Surgery Studies, Faculty of Dentistry \\ Universiti Teknologi MARA, Malaysia \\ intanbaizura3124@salam.uitm.edu.my \\ Tel: 012-2716948
}

Noor Aziella Mohd Nayan¹, Ahmad Zamir Che Daud1', Tengku Intan Baizura Tengku Jamaluddin², Siti Salwa Talib1

\begin{abstract}
This study investigated the occurrence of depression, anxiety and stress; and identified the possible stress factors among clinical dental undergraduates. A cross sectional study was conducted among 127 dental undergraduates from Universiti Teknologi MARA (UiTM) Sungai Buloh, Malaysia. Overall the scores of DASS-21 shows majority of dental undergraduates have no depression, anxiety and stress. This study also highlights the main factor affecting the dental undergraduates' depression levels is the students' educational environment. Future research on any correlation between depression levels and clinical performances is highly recommended for better understanding on this topic, and to provide better educational environment at dental institutes in Malaysia.
\end{abstract}

Keywords: Dental Undergraduates; Clinical Years; Stressors; Stress

eISSN: 2398-4287@ 2017. The Authors. Published for AMER ABRA by e-International Publishing House, Ltd., UK. This is an open access article under the CC BYNCND license (http://creativecommons.org/licenses/by-nc-nd/4.0). Peer-review under responsibility of AMER (Association of Malaysian Environment-Behaviour Researchers), ABRA (Association of Behavioural Researchers on Asians) and cE-Bs (Centre for Environment-Behaviour Studies), Faculty of Architecture, Planning \& Surveying, Universiti Teknologi MARA, Malaysia.

https://doi.org/10.21834/e-bpj.v2i6.954

\subsection{Introduction}

Dentistry is a branch of medical profession that portrays a career that is one of the most gratifying careers which provides plenty of rewards and challenges, as well as an opportunity to help people and make communities healthier. In spite of that, the educational route as a student to succeed in this profession requires steadfast, hard work and determination (Elani et al., 2014). The reality of life for a dental undergraduate is often uncertain, most especially the transition into clinical years of dental school. Some students might adopt through the transition impressively, whereas some might struggle (Mirsaifi, Daneshkazemi, Sadeghian, \& Reza, 2015).

The multifaceted nature of clinical years in dental education is like a perfect fusion of health care, art and science skills that requires serious reflection. In clinical years, a dental undergraduate will face challenges in transferring theoretical knowledge and presimulation clinical skills to treat patients, which is an extremely steep learning curve for dental undergraduates. The details oriented in physical and psychological demands within this educational journey, is like a roller coaster ride. It could shape them either emotionally or inevitably leads to psychologically distress and affects quality of life.

Occupational therapy believes that quality of life $(\mathrm{QoL})$ is vital in order to understand the individual's ideas of what constitutes QoL. In 1997, WHO defined Quality of Life as individuals' perception of their position in life in the context of the culture and value systems in which they live and in relation to their goals, expectations, standards and concerns. QoL is a broad ranging concept affected in a complex way by the person's physical health, psychological state, level of independence, social relationships, personal beliefs and their relationship to salient features of their environment.

eISSN: 2398-4287C 2017. The Authors. Published for AMER ABRA by e-International Publishing House, Ltd., UK. This is an open access article under the CC BYNCND license (http://creativecommons.org/licenses/by-nc-nd/4.0/). Peer-review under responsibility of AMER (Association of Malaysian Environment-Behaviour Researchers), ABRA (Association of Behavioural Researchers on Asians) and cE-Bs (Centre for Environment-Behaviour Studies), Faculty of Architecture, Planning \& Surveying, Universiti Teknologi MARA, Malaysia.

https://doi.org/10.21834/e-bpj.v2i6.954 
Dental education could be associated with psychological distress (Babar et al., 2015), and might directly or indirectly affect undergraduates QoL. The emotional strain is a part of occupational therapist concerns, as it could be the underlying factors that support or hinder the dental undergraduate's quality of life. A study by Kaur (2015) showed that educational environment is one of the most important factors that impact on students' satisfaction in higher education. Additionally, Keles (2012) emphasised that educational environment as one of the most significant components of the quality of life. Hussain, Jabbar, Hussain, Rehman, \& Saghir (2014) emphasized that a good educational environment could enhance quality education to students. Thus, this study was undertaken to examine the occurrence of depression, anxiety and stress besides identifying the possible stress factors among the dental undergraduates during clinical years that could potentially affect their QoL.

\subsection{Literature Review}

Quality of life; a "catch-all" term - as it is very multidimensional. The clarity of the term could be denoted based on the researcher's aims (Keles, 2012). As for this study, it evolved around the psychological aspect of the dental undergraduates, which is also an essential constituent of the quality of life. Many healthcare professionals encourage healthy lifestyle to their patients, yet failed to commit to living healthier lifestyles themselves as what they preach, and decline in their quality of life (Portero de la Cruz \& Vaquero Abellan, 2015). Generally, dental undergraduate programme is broken down into two years of theoretical classes and pre-clinical preparation, and three years of clinical skills training. Transition time from the pre-clinical to clinical years demands the undergraduates not only acquisition in theory, but also competence in skills (Radcliffe \& Lester, 2003). The clinical year's curriculum high requirements could affect the undergraduates' mental well-being (Al-Sowygh, Alfadley, Al-Saif, \& Al-Wadei, 2013). It is not a surprise that the undergraduates' QoL begin to decrease early in dental school (Jain \& Bansal, 2012).

For decades, high levels of stress have been documented among dental undergraduates (Heath, Macfarlane \& Umar, 1999) and linked with psychological distress and emotional exhaustion (Telang et al., 2013). Numerous studies evaluated dental undergraduates' psychological status from various countries (Aboalshamat, Hou, \& Strodl, 2015; Abu-Ghazaleh, Rajab, \& Sonbol, 2011; Ahmad, Yusoff, \& Razak, 2011; Anushri, Puranik, \& Yashoda, 2014; Dyrbye, Thomas, \& Shanafelt, 2006). Selye (1982) proposed a good evaluation of dental environment stress comprises of dental environment stressors, physiological reaction and cognitive response. A systematic review on stress among dental undergraduates conducted to analyse the stressors, impact of stress and indicator of stress found that many factors were related to examinations, clinical requirements and dental supervisors (Alzahem, Molen, Alaujan, Schmidt, \& Zamakhshary, 2011). Another systematic review showed dental undergraduates suffer considerable amount of stress due to clinical training and impacted well-being of the undergraduates (Elani et al., 2014). It is highly suggested to identify stress levels among the undergraduates in improving their quality of life (Alzahem et al., 2011; Jain \& Bansal, 2012).

Divaris et al. (2013) conducted a study across 17 dental schools in Colombia to investigate student-level correlation of psychological distress among dental undergraduates. The study found that levels of distress were associated with students' socioeconomic status and level of study. Mane Abhay et al. (2011) reported a significant association between depression and students' performance. The main stressors for dental undergraduates are examination, fear of failing and completing course requirements. In addition, it is believed that educational environment influenced the quality of education to the undergraduates (Hussain et al., 2014).

Literature review shows evidence of the stressors of dental education. In view of this, collaboration and aid is essential from occupational therapists, in order to play an important role in enabling people to engage in their occupations (Roley et al., 2008; Wilcock \& Townsend, 2014). The ability to control emotion influences a person's proficiency in performing task (American Occupational Therapy Association, 2014). A study showed dental anxiety, an important emotional challenge have impact on dental task performance (Storjord, Teodorsen, Bergdahl, Wynn, \& Johnsen, 2014). Thus, this study incorporates a collaboration amongst oral and maxillofacial surgeons and occupational therapists to study the level of anxiety specifically amongst UiTM dental undergraduates in clinical years, in line with recommendations from Ahmad, Md Yusoff, and Abdul Razak (2011). Their study proposed collaboration of dentistry with other expertise to intensify the quality of life among dental undergraduates. This study contributes to the occupational therapists' point of view in precisely elaborating analysis of psychological aspects among the undergraduates and to suggest an early intervention programme. Thus, this interesting collaboration aims to explore on the stressors, level of depression, anxiety and stress and the correlation between the educational environment.

\subsection{Methodology}

This cross-sectional study involved a total of 127 clinical dental undergraduates from year 3 to year 5 at Faculty of Dentistry, Universiti Teknologi MARA (UiTM) Sungai Buloh, Malaysia. Undergraduates ongoing counselling or under medications were not included in this study to avoid bias. This study was approved by the Research Ethics Committee of Universiti Teknologi Mara (Ethics No : REC/102/17). Dental Environment Stress (DES) (Garbee, Zucker, \& Selby, 1980), a self-reported questionnaire was used to identify sources of environmental stress while perceived depression, anxiety and stress level was measured using the Malay version of Depression Anxiety Stress Scale (DASS-21).

DES consists of 38 items and all items describing stressors related to dental training. The response are based on a 4 point Likert scale: 1 is "not stressful at all"; score 2 is "somewhat stressful"; score 3 is "moderately stressful"; and score 4 is "very stressful". Many dental studies utilized DES as an instrument tool (Murphy, Gray, Sterling, Reeves, \& DuCette, 2009), as DASS requires the researcher to indicate the presence of a symptom a week prior to data collection. The anxiety domain of BM DASS-21 had good 
correlation with anxiety domain in HADS (0.61) while for DASS-21 depressive domain had modest correlation with its respective domain in HADS (0.49). Thus, it proved that Bahasa Malaysia version of DASS-21 is valid and reliable to be used as a research tool (Musa, Ramli, Abdullah, \& Sarkarsi, 2011).

Data collection was done over two consecutive days, where primarily, dental undergraduates registered and consented to participate in the study. The process commenced with a briefing regarding the purpose of the study and reassurance of confidentiality of the data collected. The questionnaire forms were distributed according to a specific order. Primarily, dental undergraduates answered DES questionnaire, followed by DASS-21 questionnaire. Throughout this process, the researcher was available to attend any arisen questions regarding questionnaire.

All the responses were analysed using data analysis software (Predictive Analytics Software - PASW, formally known as SPSS ${ }^{\circledR}$ ) version 18.0 for Windows. Descriptive statistics were calculated to analyse the sources of stress and the occurrence of depression, anxiety and stress. The Kruskal-Wallis and the One Way ANOVA tests were utilised to compare the core items between different years of study (year 3, year 4 and year 5). The strength of correlation between DASS and DES score was analysed using Pearson correlation analysis.

\subsection{Results}

Majority $(40.9 \%)$ of the respondents were from year 3, with a majority of female respondents (84.3\%). Table 1 below shows the sociodemographic characteristics of the respondents.

Table 1: Socio-demographic characteristics of the respondents

\begin{tabular}{lc}
\hline Socio-demographic Characteristics & Frequency (\%) \\
\hline Year of Study & \\
Third & $52(40.9)$ \\
Fourth & $43(33.9)$ \\
Fifth & $32(25.2)$ \\
Gender & \\
Male & $20(15.7)$ \\
Female & $107(84.3)$ \\
\hline
\end{tabular}

The undergraduates in all clinical years perceived the main stress factor was triggered by the pressure to complete the graduation requirements. Subsequently, "fear of failing course/year" and "clients being late or not showing up for their appointments" were identified as the top three causes. Followed by "fear of being unable to catch up if behind" and "the amount of assigned classwork". Some of the causes of stress were overlapping among all clinical years, except "examination and grades" which occur to be top five stress factors in year 4 and "expectations of dental school and what in reality" it is like in year 5 . The precipitating factors of stress by different years of study is shown in Table 2 .

Table 2: Top five causes among all respondents and highest mean score by clinical year

\begin{tabular}{clc}
\hline Year & \multicolumn{1}{c}{ Causes of Stress } & Score Mean (SD) \\
\hline \multirow{3}{*}{ All clinical } & Completing graduation requirement & $3.86(0.50)$ \\
years & Fear of failing course or year & $3.70(0.61)$ \\
& Clients being late or not showing for their appointments & $3.66(0.58)$ \\
& Fear of being unable to catch up if behind & $3.46(0.76)$ \\
& Amount of assigned classwork & $3.44(0.79)$ \\
\hline & Completing graduation requirements & $3.85(0.50)$ \\
3 & Fear of failing course or year & $3.73(0.56)$ \\
& Amount of assigned classwork & $3.60(0.66)$ \\
& Fear of being unable to catch up if behind & $3.52(0.67)$ \\
& Clients being late or not showing for their appointments & $3.46(0.67)$ \\
\hline & Completing graduation requirements & $3.84(0.57)$ \\
& Clients being late or not showing for their appointments & $3.77(0.53)$ \\
& Fear of failing course or year & $3.58(0.73)$ \\
& Examination and grades & $3.40(0.66)$ \\
& Responsibilities of comprehensive client care & $3.37(0.66)$ \\
\hline & Completing graduation requirements & $3.90(0.40)$ \\
& Clients being late or not showing for their appointments & $3.84(0.37)$ \\
& Fear of failing course or year & $3.81(0.48)$ \\
& Fear of being unable to catch up if behind & $3.52(0.77)$
\end{tabular}

The overall score for DES questionnaire was 90.82 with the highest stress recorded from year 5 , followed by year 3 and year 4 . One Way ANOVA found there was significant difference in DES score across years of study $(p=0.048)$. However, further post hoc test using Tukey test (table 3) showed that there was no significant difference in DES score between different pairs of the years of study. 
Table 3: Difference between DES score between difference years of study

\begin{tabular}{ccc}
\hline Pairs & Mean Difference & p-value \\
\hline Year 3 - Year 4 & 7.11 & 0.069 \\
Year 3 - Year 5 & -0.28 & 0.096 \\
Year 4 -Year 5 & -7.39 & 0.104 \\
\hline
\end{tabular}

Result of DASS-21 showed that majority of the respondents have no depression, anxiety and stress throughout their undergraduate study. Most of the respondents in year 3 are in normal range of depression, anxiety and stress. However, 15.4\%, 25\%, $1.9 \%, 5.8 \%$ of the respondents are having mild, moderate, severe and extremely severe depression respectively. As for anxiety status, $5.8 \%$ have mild anxiety, followed by $28.8 \%$ to $17.3 \%$ are with moderate anxiety to extremely severe anxiety. $61.5 \%$ of the respondents are stress free but ranging from $11.5 \%$ to $1.9 \%$, the rest are having mild to extremely severe stress. Generally, most of the respondents from year 4 experience normal range of depression, anxiety and stress. Notably, $4.7 \%$ are having extremely severe depression, $16.3 \%$ have extremely severe anxiety and $9.3 \%$ are in severe stress. As for year 5 respondents, most of the respondents are in normal range of depression and stress, but moderate anxiety. Table 4 below shows the detailed result of the DASS-21 questionnaire among the respondents.

Table 4: Outcome of DASS-21 Among Clinical Years

\begin{tabular}{lrrrr}
\hline \multicolumn{1}{c}{ Category } & $\begin{array}{r}\text { Total, } \\
\mathbf{n}(\%)\end{array}$ & \multicolumn{1}{r}{$\begin{array}{r}\text { Year 3 } \\
\mathbf{n}(\%)\end{array}$} & \multicolumn{1}{r}{$\begin{array}{r}\text { Year 4 } \\
\mathbf{n}(\%)\end{array}$} & \multicolumn{1}{r}{$\begin{array}{r}\text { Year 5 } \\
\mathbf{n}(\%)\end{array}$} \\
\hline Depression & & & & \\
$\quad$ Normal & $70(55.1)$ & $27(51.9)$ & $22(51.2)$ & $21(65.6)$ \\
Mild & $23(18.1)$ & $8(15.4)$ & $12(27.9)$ & $3(9.4)$ \\
Moderate & $25(19.7)$ & $13(25.0)$ & $6(14.0)$ & $6(18.8)$ \\
Severe & $4(3.1)$ & $1(1.9)$ & $1(2.3)$ & $2(6.3)$ \\
Extremely Severe & $5(3.9)$ & $3(5.8)$ & $2(4.7)$ & $0(0.0)$ \\
Anxiety & & & & \\
$\quad$ Normal & $43(33.9)$ & $16(30.8)$ & $17(39.5)$ & $10(31.3)$ \\
Mild & $7(5.5)$ & $3(5.8)$ & $1(2.3)$ & $3(9.4)$ \\
Moderate & $41(32.3)$ & $15(28.8)$ & $14(32.6)$ & $12(37.5)$ \\
Severe & $15(11.8)$ & $9(17.3)$ & $4(9.3)$ & $2(6.3)$ \\
Extremely Severe & $21(16.5)$ & $9(17.3)$ & $7(16.3)$ & $5(15.6)$ \\
Stress & & & & \\
$\quad$ Normal & $71(55.9)$ & $32(61.5)$ & $19(44.2)$ & $20(62.5)$ \\
Mild & $22(17.3)$ & $6(11.5)$ & $12(27.9)$ & $4(12.5)$ \\
Moderate & $23(18.1)$ & $11(21.2)$ & $8(18.6)$ & $4(12.5)$ \\
Severe & $9(7.1)$ & $2(3.8)$ & $4(9.3)$ & $3(9.4)$ \\
Extremely Severe & $2(1.6)$ & $1(1.9)$ & $0(0.0)$ & $1(3.1)$ \\
\hline
\end{tabular}

In depression score, Kruskal Wallis test showed that there was no significant difference in depression score between different years of study $(p=0.314)$. As for anxiety status score, One Way ANOVA showed there was no significant difference in anxiety score between different years of study $(p=1.000)$. The stress score was also analysed using One Way ANOVA showed there was no significant difference in stress score between different years of study $(p=0.765)$. The Pearson correlation analysis was done to determine the correlation between DES and DASS-21 score. From the test, there was a significant fair positive correlation between DES and depression score $(p=0.001, r=0.30)$. However, there were no significant correlation present between $D E S$ and anxiety score $(p=0.229)$, and also between DES and stress score $(p=0.107)$.

\subsection{Discussion}

On the whole, the findings of this study contradicted the general impression that dental undergraduates experience high level of psychological distress (Alzahem et al., 2011). DASS-21 is not a clinical diagnoses tools (Musa, Fadzil, \& Zain, 2007), but it is a good screening instrument that can be used in any setting (Henry \& Crawford, 2005). Even so, there are still few of the undergraduates are in the range of mild to extremely severe category, which need urgent interventions to prevent further deterioration in academic performance (Stewart-brown et al., 2000). Generally, the scores of DASS-21 shows majority of dental undergraduates have no depression, anxiety and stress. This is totally contradict to the current findings from (Basudan, Binanzan, \& Alhassan, 2017), which showed the occurrence of depression, anxiety and stress were high and implied half of the dental undergraduates. This also inconsistent with findings that stated many dental undergraduates tend to have depression, anxiety and stress (Dudău, Sfeatcu, Funieru, \& Dumitrache, 2015). This could be due to many factors that influences the psychological state of undergraduates such as conducive learning environment (Hussain et al., 2014).

As for comparison of DASS-21 between different years of study, there are no significant difference in depression, anxiety and stress score. However, year 5 undergraduates are having slightly higher percentage of anxiety than year 3 and year 4 . Consistently with a study by Shamsudin et al., (2013) stated that senior group tend to have more anxiety. This might be explained as year 5 is the last year of undergraduates, it will be challenging to strive in the final year to graduate on time and secure the future. Furthermore, year 5 undergraduates have to complete their clinical requirements as a pre-requisite to sit for their professional exams. Otherwise, 
there will be extension of studies based on their requirement status of Minimal Clinical Experience (MCE) as per sanctioned by the Deans Council (Malaysia). DES score was used to perceive the sources of stress. There are some overlap causes of stress by years of study. Overall, the academic performance category was the most provoking factor in every year of study which are completing graduation requirement, fear of failing course or year, fear of unable to catch up and amount of assigned classwork. Based on previous findings, these are the undergraduates' effort to fulfil academic performance requirement. The clinical logbook achievement could cause emotional challenge (Rajab, 2001; Yap, Bhole, \& Teo 1996). The undergraduates' judgment of workload is one of the stressful factors (Acharya, 2003; Sanders \& Lushington, 2002). Similarly, a recent study found that all this factors could lead to fear among the undergraduates in failing (Divaris et al., 2013).

Clients being late or not turning up for their appointment and responsibilities of comprehensive client care are another main concern among the undergraduates due to completion in the clinical requirement requires full cooperation from the clients (Gorter et al., 2008). The significant different in DES score between years of study might be due to different clinical tasks but the post hoc test showed there was no significance different, as it might be some interaction between year 3 , year 4 and year 5 . There is fair strength correlation between DES score and depression. The higher the DES score, the higher is the depression level. This might be due to inadequate compensating response to the persistent provoking factors as listed in DES can result in higher depression level. Most of the undergraduates enrolled in this institution were the best students with high academic achievements during high school and preuniversity. The current BDS programme standard (Academic Unit, Faculty of Dentistry, UiTM) for a dental undergraduate is a minimum CGPA of 3.92. However, the prolonged educational stressor throughout their study might trigger the depressive symptoms (Bostanci et al., 2005). The shortcomings for this study would be the assessments were only to rule out the stress factors and occurrence level of depression, anxiety and stress. There is no comparison to the academic performance to clearly deduce the effects. The undergraduates were solely trained at UiTM, which is not representative of all dental undergraduates in Malaysia. This collaborative study between the two fields; occupational therapy and dentistry could be further enhanced in future research to investigate other implications to the undergraduates, especially with consideration of the effect of distress issues on academic performance.

\subsection{Conclusion}

This study identified the sources of stress and the occurrence level of depression, anxiety and stress among dental undergraduates in clinical years which, in turn affect quality of life to the undergraduates. In the dental field, the triggering factors should be highlighted to clinical educators and administers in order to make necessary amendments in reviewing the dental syllabus to reduce the stressinducing factors. The findings of this study is essential to occupational therapists' perspective to explore and to analyse psychological status among dental professionals, to promote better well-being in this field. As Clark et al. (2012) recommended, lifestyle redesigning is one of the occupational therapy approach that could promote good mental well-being and improve quality of life. Some of the stressful events cannot be avoided in pursuing a dental degree. It is essential that precautionary steps should be implemented to improve dental undergraduates coping mechanism in developing good mental well- being and gaining satisfaction in life. Hence improving a dental undergraduate's QoL.

\section{Acknowledgements}

Heartiest gratitude to all the participants for their time and commitment. This study was funded by LESTARI grant (600-IRMI/DANA 5/3/LESTARI 0070/2016), Universiti Teknologi MARA (UiTM), Malaysia.

\section{References}

Aboalshamat, K., Hou, X. Y., \& Strodl, E. (2015). Psychological well-being status among medical and dental students in Makkah, Saudi Arabia: a cross-sectional study. Med Teach, 37 Suppl 1(June), S75-81.

Abu-Ghazaleh, S. B., Rajab, L. D., \& Sonbol, H. N. (2011). Psychological stress among dental students at the University of Jordan. J Dent Educ, 75(8), 1107-1114.

Acharya, S. (2003). Factors affecting stress among Indian dental students. Journal of Dental Education, 67(10), 1140-1148.

Ahmad, M. S., Md Yusoff, M. M., \& Abdul Razak, I. (2011). Stress and its relief among undergraduate dental students in Malaysia. The Southeast Asian Journal of Tropical Medicine and Public Health, 42(4), 996-1004.

Ahmad, M. S., Yusoff, M. M., \& Razak, I. A. (2011). Stress and Its Relief Among Undergraduate Dental Students in Malaysia. Southeast Asian J Trop Med Public Health, 42(4), 996-1004.

Al-Sowygh, Z. H., Alfadley, A. A., Al-Saif, M. I., \& Al-Wadei, S. H. (2013). Perceived causes of stress among Saudi dental students. King Saud University Journal of Dental Sciences, 4(1), 7-15.

Alzahem, A. M., Molen, H. T. Van Der, Alaujan, A. H., Schmidt, H. G., \& Zamakhshary, M. H. (2011). Stress amongst dental students : a systematic review, 15 , 8-18.

American Occupational Therapy Association. (2014). Occupational Therapy Practice Framework: Domain and Process (3rd Edition). American Journal of Occupational Therapy, 68(Supplement_1), S1-S48. 
Anushri, M., Puranik, M., \& Yashoda, R. (2014). Relationship between psychological well-being and perceptions of stress among undergraduate dental students in Bengaluru city: A cross-sectional study. Journal of Indian Association of Public Health Dentistry, 12(4), 283.

Babar, M. G., Hasan, S. S., Ooi, Y. J., Ahmed, S. I., Wong, P. S., Ahmad, S. F., .. Malik, N. A. (2015). Perceived sources of stress among Malaysian dental students. International Journal of Medical Education, 6, 56-61.

Basudan, S., Binanzan, N., \& Alhassan, A. (2017). Depression , anxiety and stress in dental students, 179-186.

Bostanci, M., Ozdel, O., Oguzhanoglu, N. K., Ozdel, L., Ergin, A., Ergin, N., ... Karadag, F. (2005). Depressive symptomatology among university students in Denizli, Turkey: prevalence and sociodemographic correlates. Croatian Medical Journal, 46(1), 96-100.

Clark, F., Jackson, J., Carlson, M., Chou, C.-P., Cherry, B. J., Jordan-Marsh, M., ... Azen, S. P. (2012). Effectiveness of a lifestyle intervention in promoting the wellbeing of independently living older people: results of the Well Elderly 2 Randomised Controlled Trial. Journal of Epidemiology and Community Health, 66(9), 782-790.

Divaris, K., Mafla, A. C., Villa-Torres, L., Sánchez-Molina, M., Gallego-Gómez, C. L., Vélez-Jaramillo, L. F., ... Polychronopoulou, A. (2013). Psychological distress and its correlates among dental students: a survey of 17 Colombian dental schools. BMC Medical Education, $13,91$.

Dudău, D. P., Sfeatcu, I. R., Funieru, C., \& Dumitrache, M. A. (2015). Professional Stress in Relation to Anxiety, Depression and Irrational Beliefs Among Dental and Psychotherapy Students. Procedia - Social and Behavioral Sciences, 187, 158-162.

Dyrbye, L. N., Thomas, M. R., \& Shanafelt, T. D. (2006). Systematic Review of Depression , Anxiety , and Other Indicators of Psychological Distress Among U . S . and Canadian Medical Students, 81(4), 354-373.

Elani, H. W., Allison, P. J., Kumar, R. A., Mancini, L., Lambrou, A., \& Bedos, C. (2014). A Systematic Review of Stress in Dental Students. Journal of Dental Education - $78(2), 226-242$.

Garbee, W. H., Zucker, S. B., \& Selby, G. R. (1980). Perceived Sources of Stress Among Dental Students. The Journal of the American Dental Association, 100(6), 853-857.

Gorter, R., Freeman, R., Hammen, S., Murtomaa, H., Blinkhorn, A., \& Humphris, G. (2008). Psychological stress and health in undergraduate dental students: Fifth year outcomes compared with first year baseline results from five European dental schools. European Journal of Dental Education, 12(2), 61-68.

Henry, J. D., \& Crawford, J. R. (2005). The short-form version of the Depression Anxiety Stress Scales (DASS-21): construct validity and normative data in a large nonclinical sample. The British Journal of Clinical Psychology / the British Psychological Society, 44(Pt 2), 227-39.

Hussain, S., Jabbar, M., Hussain, Z., Rehman, Z., \& Saghir, A. (2014). The students' satisfaction in higher education and its important factors: A comparative study between Punjab and AJ\&K, Pakistan. Research Journal of Applied Sciences, Engineering and Technology, 7(20), 4343-4348.

Jain, A., \& Bansal, R. (2012). Stress among Medical and Dental Students: A Global Issue. Iosr, 1(5), 5-7.

Shamsuddin, K., Fadzil, F., Ismail, W. S. W., Shah, S. A., Omar, K., Muhammad, N. A., ... \& Mahadevan, R. (2013). Correlates of depression, anxiety and stress among Malaysian university students. Asian journal of psychiatry, 6(4), 318-323.Kaur, H. (2015). Satisfaction of Students towards Quality in Higher Education- A Study of Higher Education Sector Punjab ( India ), 8(6), 83-91.

Keles, R. (2012). The Quality of Life and the Environment. Procedia - Social and Behavioral Sciences, 35(December 2011), 23-32.

Mirsaifi, R., Daneshkazemi, A., Sadeghian, H. A., \& Reza, M. (2015). Evaluating Stress Level Causes by Studying Environment and Related Factors in Dental Students of Yazd Dental College in 2014. Avicenna J Dent Research, 7(1), 1-4.

Murphy, R. J., Gray, S. A., Sterling, G., Reeves, K., \& DuCette, J. (2009). A comparative study of professional student stress. Journal of Dental Education, 73(3), 32837.

Musa, R., Fadzil, M. A., \& Zain, Z. (2007). Translation , validation and psychometric properties of Bahasa Malaysia version of the Depression Anxiety and Stress Scales ( DASS ), 8(2), 82-89.

Musa, R., Ramli, R., Abdullah, K., \& Sarkarsi, R. (2011). Concurrent validity of the depression and anxiety components in the Bahasa Malaysia version of the Depression Anxiety and Stress scales (DASS). ASEAN Journal of Psychiatry, 12(1), 66-70.

Portero de la Cruz, S., \& Vaquero Abellan, M. (2015). Professional burnout, stress and job satisfaction of nursing staff at a university hospital. Revista Latino-Americana de Enfermagem, 23(3), 543-552.

Roley, S. S., DeLany, J. V., Barrows, C. J., Brownrigg, S., Honaker, D., Sava, D. I., ... Lieberman, D. (2008). Occupational Therapy Practice Framework: Domain \& Process 2nd Edition. The American Journal of Occupational Therapy (Vol. 62). Sanders, A., \& Lushington, K. (2002). Effect of perceived stress on student performance in dental school. J Dent Educ., 66(January), 75-81.

Storjord, H. P., Teodorsen, M. M., Bergdahl, J., Wynn, R., \& Johnsen, J. A. K. (2014). Dental anxiety: A comparison of students of dentistry, Biology, And psychology. Journal of Multidisciplinary Healthcare, 7, 413-418.

Telang, L. A., Nerali, J. T., Telang, A., \& Chakravarthy, P. V. K. (2013). Perceived sources of stress among Malaysian dental students. European Journal of General Dentistry, 2(3), 300 .

World Health Organization Measuring quality of life: The World Health Organization quality of life instruments. http://www.who.int/mental_health/media/68.pdf

Yap, A. U., Bhole, S., \& Teo, C. S. (1996). A cross-cultural comparison of perceived sources of stress in the dental school environment. Journal of dental education, 60(5), 459-464. 